University of Wollongong

Research Online

Faculty of Commerce - Papers (Archive)

Faculty of Business and Law

June 2002

\title{
Diffusion of R\&D within the Australian wine industry
}

D. K. Aylward

University of Wollongong, daylward@uow.edu.au

Follow this and additional works at: https://ro.uow.edu.au/commpapers

Part of the Business Commons, and the Social and Behavioral Sciences Commons

\section{Recommended Citation}

Aylward, D. K.: Diffusion of R\&D within the Australian wine industry 2002.

https://ro.uow.edu.au/commpapers/52

Research Online is the open access institutional repository for the University of Wollongong. For further information contact the UOW Library: research-pubs@uow.edu.au 


\section{Diffusion of R\&D within the Australian wine industry}

\section{Keywords}

diffusion, R\&D, wine industry

\section{Disciplines}

Business | Social and Behavioral Sciences

\section{Publication Details}

This article was originally published as Aylward, D, Diffusion of R\&D within the Australian wine industry, Prometheus, 20(4), 2002. Copyright Taylor \& Francis. Journal available online here. 


\title{
Diffusion of R\&D within the
}

\section{Australian Wine Industry}

\author{
David K. Aylward \\ Faculty Research Manager, \\ Faculty of Commerce \\ University of Wollongong
}

\section{Introduction}

Research into the process of innovation and the diffusion of knowledge has focused on the growing significance of collaborative research arrangements between universities, public sector organisations, industry funded R\&D corporations and business. As Leydesdorff and Etzkzowitz explain, an interesting feature of this collaboration is the role of government in stimulating these alliances (Leydesdorff \& Etzkzowitz 1996). Governments around the world are increasingly concerned with directing public national research effort towards commercial outcomes and with constructing the appropriate research infrastructure for supporting innovation. Gibbons et al have approached this issue by addressing the larger discussion of knowledge intensity and diffusion and the interesting theoretical debate that is arising about knowledge production in the context of application (Gibbons et al, 1994).

Most detailed studies of the collaborative role of government in R\&D have focused on manufacturing. While some studies have focused on the role of government in supporting the diffusion of knowledge in agricultural sectors, few have investigated the role of R\&D in sectors such as the wine industry. Yet in Australia this sector currently exports around $\$ 1.5$ billion worth of wine, has a significant growth rate relative to the country's other leading exporters and is considered a world leader in wine making and viticultural innovation.

It is however, an industry that is widely dispersed geographically, dominated by a small number of large firms with a very large number of small firms creating significant market, product and structural diversity. It is this set of rather unique characteristics which lead to the critical issue of how knowledge is diffused within the industry and how effective that 
diffusion is. It is an issue that has also been identified as problematic by the industry's intermediary body, the Grape and Wine Research Development Corporation (GWRDC), which is the major research and training coordinator and R\&D funding body for the Australian wine industry. As such, one of its main priorities is to establish mechanisms for effective knowledge diffusion.

\section{Aims of the Study}

The present study concerns itself with the various mechanisms and their effectiveness in diffusing viticultural and oenological research, as well as training knowledge throughout the Australian wine industry. The central question relating to this is: do smaller, regional wine operators have the same access and opportunity to this knowledge as those located in what I refer to as the industry's R\&D 'epicentre'. 'Three specific objectives focusing on this question have guided the study. They are:

1. to examine the extent to which the research systems is supplying the industry as a whole;

2. to provide a preliminary comparison of $R \& D$ knowledge and awareness levels between large, medium and small industry operators outside the 'epicentre';

3. to investigate the concern raised by the Committee of Inquiry into the Winegrape and Wine Industry, that the benefits of national R\&D may not be flowing through to the regional operators; and

4. to provide a brief analysis and comparative breakdown of training issues and trends and how these may be influenced by company size and positioning within the industry;

\section{Industry Overview}

There are now approximately 1320 wine operators in Australia (Wine Online, March 2001), with the number growing on an almost weekly basis (Osmond \& Anderson, 1998). Of these 1320 operators, the vast majority (around 1100) are boutique/small operators. These range from a husband/wife team with fewer than 5 employees, often 1 or 2 and crushing less than 50 tonnes of grapes a year, to established private operators with 10-20 employees, crushing up to 1000 tonnes annually (Australian Wine Online 2001). 
Table 1 Australian Wine Production 2000

\begin{tabular}{|c|c|}
\hline Wine Production & No. of Operators \\
\hline Less than 20 tonnes & 371 \\
\hline 20 to 49 tonnes & 296 \\
\hline 50 to 99 tonnes & 199 \\
\hline 100 to 249 tonnes & 169 \\
\hline 250 to 499 tonnes & 75 \\
\hline 500 to 999 tonnes & 49 \\
\hline 1,000 to 2,499 tonnes & 49 \\
\hline 2,500 to 4,999 tonnes & 27 \\
\hline 5,000 to 9,999 tonnes & 29 \\
\hline 10,000 or more & 42 \\
\hline Unknown or unspecified & 12 \\
\hline Total & 1318 \\
\hline
\end{tabular}

A significant majority of these operators are both grape growers and wine makers, a changing trend from 20 years ago, when it was usually one or the other (mostly grower) (Beeston, 2000). The other noticeable trend is the export orientation of the industry. This is no longer reserved for the larger, well established companies. Even the smallest boutique wineries are now actively pursuing the export market, although with varying degrees of success.

As of December 2000, there was roughly 146,177 hectares under vine in Australia, with a vintage of 1,147,018 tonnes. Total wine produced for 2000 equalled 806.4 million litres. Domestics sales of Australian wine were a record 369.3 million litres, while exports accounted for 310.5 million litres, or $\$ 1.5$ billion. This represented a volume rise of $20.3 \%$ over the previous year's exports. (Australian \& New Zealand Wine Industry Directory, 2001)

Table 2 Wine Exports from Australia for 2000

\begin{tabular}{|c|c|c|c|}
\hline Country & $\underline{\text { Volume ML }}$ & Value $\$ \mathrm{~A}(\mathrm{~m})$ & $\begin{array}{l}\text { \% Change in } \\
\text { Value over } \\
\text { previous Yr }\end{array}$ \\
\hline UK & 149.6 & 626.2 & 14.1 \\
\hline USA & 59.8 & 382.1 & 49.4 \\
\hline $\mathrm{NZ}$ & 20.5 & 74.2 & 10.1 \\
\hline Canada & 14.9 & 88.9 & 56.3 \\
\hline
\end{tabular}




\begin{tabular}{|l|r|r|r|}
\hline Germany & 9.7 & 41.8 & 41.1 \\
\hline Netherlands & 9.4 & 39.7 & 29.4 \\
\hline Ireland & 7.7 & 41.5 & 24.6 \\
\hline Japan & 5.5 & 30 & 18.2 \\
\hline Sweden & 4.9 & 18.8 & 6.7 \\
\hline Switzerland & 4.5 & 28.7 & 22.1 \\
\hline Belgium-Lux & 3 & 13.9 & -.07 \\
\hline Denmark & 2.9 & 12.6 & 18 \\
\hline France & 2.6 & 6.8 & 13.3 \\
\hline Norway & 2.6 & 10.3 & 4.9 \\
\hline Singapore & 2.3 & 16 & 20.5 \\
\hline Rest & 10.6 & 55.9 & 7.6 \\
\hline World & 310.5 & 1487.4 & 24.5 \\
\hline
\end{tabular}

Source: Aust. NZ Wine Industry Directory 2001

As is shown in the above table, the UK, USA and NZ markets now account for around $74 \%$ of all exports (volume), with the UK alone consuming $48 \%$ of our. While the UK market is expected to reach maturity within the next five years, the United States represents Australia's next big export market, with expectations that it will approach the UK within the next decade. Other emerging and strategically important markets include Germany, Canada and Japan.

In 2000, there were 571 wine operators in Australia that were registered as exporters. To put this figure in perspective however, the twenty largest exporters account for over $95 \%$ of export value. Nevertheless, this percentage is decreasing as more operators seek export markets for their product and become more adept at securing longer term contracts, rather than the one-off style contracts that currently dominate small operator trade. Because as in most industries, export activity is leading to greater levels of innovation, it is envisaged that the increase in both the levels of export and the numbers of operators involved will act as a 'trigger' for greater diffusion of $\mathrm{R} \& \mathrm{D}$ throughout the industry.

\section{Industry R\&D Overview}

R\&D, namely oenological and viticultural R\&D, are seen as the Australian wine industry's great advantage. Australia is still one of the smaller wine producers and exporters, accounting 
for about $3 \%$ of the world's production, but its spectacular rise from mediocrity throughout the 1970 s and 80 s to perhaps the world's leading producer in terms of quality and value for money, is a result of this leading edge R\&D. The industry's high-tech approach to wine making through computerised monitoring and adjustment at every stage of the process, linked to the same high-tech approach to vineyard management and soil analysis has created a very distinct 'gap' in quality between this and the 'Old World' producers' approach. The coordination of this R\&D through the GWRDC has ensured that Australia remains at the forefront of oenological and viticultural R\&D, with no other country with the possible exception of New Zealand, demonstrating the same unified approach (GWRDC, 1999).

However, the wine industry in Australia is now largely characterised by small operators who, because results are not always commercially viable, are unable to undertake R\&D on an individual basis. Oenological and viticultural $R \& D$ are only carried out by qualified and endorsed scientists, staff and institutions', almost all of whom are based in the South Australian 'epicentre'. The Australian Wine Research Institute and the University of Adelaide carry out a significant amount of this R\&D and are contracted directly through the GWRDC. Although they often sub-contract certain aspects of the R\&D, such as vine and soil analysis, it usually remains within the 'epicentre' of South Australian institutions. This situation is feeding a 'cultural gap' in R\&D knowledge. It is the structure of future collaboration and the mechanisms employed which have the potential to address this problem, as outlined later in the paper.

Funding for the industry's R\&D is derived from the following sources:

- industry levies collected from the grape and wine producers on tonnes crushed;

- government funding provided through matching grants; and

- government funding for project grants.

GWRDC funding allocation is divided into two main groups: the Grape account and the Wine account. For the 1999/2000 year, the Grape account had a total allocation of \$4.54 million and the Wine account had a total allocation of $\$ 4.67$ million (GWRDC). In addition, a number of state governments and the larger wine companies also conduct their own in-house research. In 1999/00 figures from the GWRDC, more than $\$ 23$ million was spent on R\&D in total by the industry. The division of this expenditure is: 
- $48 \%$ by the Commonwealth (including GWRDC);

- $28 \%$ by industry; and

- $24 \%$ by State government

It is primarily in this industry sponsored $R \& D$ that links with public sector institutions have been developed through collaborative structures aimed at bringing together experts in oenology, viticulture, compliance, residue monitoring, interpretation and strategic planning.

Following, are the core wine R\&D bodies in Australia.

\section{Grape and Wine Research \& Development Corporation (GWRDC)}

An intermediary agency (GWRDC), sponsored by both industry and government organisations is responsible for 'developing, managing and maintaining these collaborative arrangements' (Turpin \& Aylward, et al1996). The GWRDC was established in 1991 as a statutory authority under provisions of the Primary Industries and Energy Research and Development Act 1989. The corporation seeks coinvestors to contribute to the support of both strategic and basic R\&D as well as to encourage regional innovation through technology adoption activity (GWRDC 1999). It enjoys a close relationship with other key R\&D providers including the Australian Wine Research Institute, the CSIRO and the various state departments of agriculture. The GWRDC also consults directly with industry service providers such as the Cooperative Research Centre for Viticulture (CRCV) and the Australian Wine and Brandy Corporation, as well as with other R\&D Corporation programs (GWRDC 1999).

The two core R\&D contractors with which the GWRDC cooperates are the Australian Wine Research Institute and the Cooperative Research Centre for Viticulture (CRCV).

\section{The Australian Wine Research Institute}

The Institute was incorporated under the South Australian Companies Act in 1955. It has assumed and extended upon the activities of the Oenological Research Committee, which 
previously had been established under an arrangement between the Commonwealth Scientific and Industrial Research Organization (CSIRO), the University of Adelaide and the Australian Wine Board (now the Australian Wine and Brandy Corporation) to undertake oenological and viticultural research for the Australian wine industry. (The Australian Wine Research Institute Home Page, 2001)

Its core objectives are to carry out applied research and to service the needs of winemakers, be involved in both undergraduate and postgraduate teaching and to coordinate information on oenology and viticulture research to the benefit of the Australian wine industry. (Turpin \& Aylward, et at 1996).

\section{Cooperative Research Centre for Viticulture}

The CRCV was established in 1992, initially existing as a collaborating mechanism between Adelaide and Charles Sturt universities, three state agriculture departments, the CSIRO, the Australian Wine Research Institute and an agricultural technology company. Research at the CRCV can be classified into three main groups:

- biotechnology research into grape quality improvement;

- viticulture;

- education and technology transfer

Figure 1: Wine Industry R\&D Structure

GWRDC Partner Groups

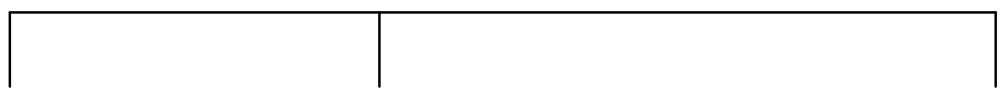




\section{Statutory levy contributors}

Winegrape growers

Winemakers
Commonwealth Government
GWRDC Provider partners/coinvestors

\begin{tabular}{|c|c|}
\hline \multicolumn{1}{c|}{$\begin{array}{c}\text { Funding } \\
\text { providers }\end{array}$} & Services/goods providers \\
\hline $\begin{array}{c}\text { Industry } \\
\text { Commonwealth }\end{array}$ & $\begin{array}{l}\text { Technology and } \\
\text { communication networks } \\
\text { Information deliverers } \\
\text {-Media } \\
\text {-Industry associations } \\
\text { Financial services }\end{array}$ \\
\hline
\end{tabular}

Skills/knowledge providers

State agricultural agencies

Universities

Private research agencies

CSIRO

CRCs

Consultants

Resellers

Overseas agencies

Source: GWRDC

A feature of the industry structure is that many smaller operators are entering the export market for the first time. Is the national investment in research serving to benefit this growing number of small but specialised exporters? 


\section{Survey Operator Characteristics}

As part of the study upon which this paper is based, a national survey questionnaire, including the four selected regions, was sent to wine operators. The aim of the survey was to profile the industry's R\&D and training and to assess the extent to which the smaller regional operators were able to access these knowledge flows in order to link into the industry's 'epicentre'.

Of the 41 national operators surveyed/interviewed, 32 were sole proprietor/partnerships, 5 were subsidiaries of larger companies and 4 were publicly listed companies with a market capitalisation of at least $\$ 80$ million and up to $\$ 1.6$ billion. A significant majority had less than 10 employees, 6 had more than 100 employees and 2 had more than 1,000 employees. The vast majority (34) were both wine makers and growers, which is in line with the national trend. Six were solely growers and only one was solely a wine maker.

In terms of annual crush, about a quarter crushed less than 50 tonnes, another quarter crushed between 50 and 200 tonnes, while at the other end of the scale, 4 crushed between 20,000 and 50,000, 1 crushed between 50,000 and 100,000 tonnes and 1 crushed over 200,000 tonnes.

Three quarters of all operators surveyed exported their product. The remaining quarter hoped to within the next three years. As a percentage of their annual turnover, a quarter of respondents claimed that exports accounted for more than 50\%, and more than half claimed that export value had risen as a percentage over the past three years.

\section{Methodology of the Study}

The study has been carried out over a six month period and involved two stages:

1. A national pilot survey of wine operators was conducted.

2. An analysis based on in-depth phone and field interviews with a smaller sample of respondents across four regions was carried out. 
The study focused on potential 'users of research', ('R\&D pull' approach) rather than the research institutions within the industry. It was restricted to these participants simply because as end users of the R\&D, it was felt their perspective was the most appropriate and would provide greatest value in determining the extent to which knowledge was being diffused within the industry.

\section{Stage One}

A literature review was first conducted in order to establish the parameters of inquiry and to help refine survey and interview issues. A survey instrument was then developed and delivered to 41 industry respondents. These respondents were selected to provide a broad cross-section of geographic regions, various levels of industry concentration and operator size.

Stage Two

Preliminary results from Stage One then fed into the qualitative aspect of the study, providing background information and guidelines for the eleven in-depth interviews.

These field interviews were carried out with participants in the Mudgee, Hunter, Shoalhaven and Canberra regions, focusing on small, medium and large operators in areas that are considered 'regional' to South Australia - the wine industry’s R\&D ‘epicentre'.

As well as adding to the quantitative information collected on R\&D opportunities and barriers facing regional operators, these in-depth interviews provided the study with a valuable insight into the issues which help shape and characterise the industry and its utilisation of R\&D.

\section{Regional Snapshots}


The study which supports this paper focuses on four regions, including the Hunter Valley, Mudgee, Shoalhaven and Canberra District. These regions represent a spectrum of traditional to new and heavily tourist oriented to low tourist traffic areas.

The four regions are quite distinct, each with their unique characteristics influenced by climate, geographic position, tourism and their mix of wine operators. None of the regions enjoy a close proximity to wine focused R\&D institutions of South Australia and western NSW, with all considered to be operating on the periphery of the industry's 'epicentre'. This may seem surprising given the reputation of regions such as the Hunter, but the study will show that concentration of oenological and viticultural $R \& D$ resources in the wine industry is intense.

\section{Canberra District}

The Canberra wine district consists primarily of small boutique wineries, including fairly well known names such as Doonkuna, Lark Hill, Clonakilla and Kyeema Estate. These wineries are clustered outside the Territory's borders in two major groups, the Yass Valley around Murrumbateman and around the shores of Lake George. The one exception to this rule is the recent presence of wine giant BRL Hardy, which in 1997 entered into agreement with the Territory's government and established a 2000-tonne winery surrounded by 250 hectares of vines. It now dominates the region in terms of size, technical sophistication and as a tourism drawcard (Halliday, 1999).

Although enjoying a relatively high profile as a wine region, the Canberra district is fairly new, with first plantings in 1971. Many of the region's wineries have been established by local ex-bureaucrats, doctors and lawyers with little oenological, viticultural or marketing knowledge. Until recently, there has been little technical qualification or sophistication in the region, with much of the technical work being outsourced to consultants. However, the arrival of BRL Hardy promises to change this as wines from its new centre come onto the market in 2002-03 (Halliday, 1999). 


\section{Shoalhaven}

In national terms, the Shoalhaven is one of the smaller and less well known wine districts. It is also relatively new, with the first established wineries in the early 1970s. Despite these factors, it is already gaining a reputation for producing quality wines, with at least one of its wineries winning prestigious wine quality and tasting awards on a regular basis (Interview Julie Cambewarra Winery). All the region's wineries are very much in the boutique category, each with less than five employees and all but one crushing less than 100 tonnes annually. There are currently four established estates; Coolangatta, Cambewarra, The Silos and Jasper Valley Wines, with a fifth opening in the near future.

The region is primarily a wine-tourism region and relies heavily on cellar door sales for its economic viability. The growth for the region however, seems limited, as most new wineries and vineyard developments are emerging west of the Great Divide mountain range a hundred miles from the coast in NSW (Halliday, 1999).

\section{Mudgee}

In contrast to the Canberra district and Shoalhaven, Mudgee is one of Australia's oldest wine regions, with first plantings in 1858. However, despite its age and the presence of such companies as Poet's Corner and Montrose, both crushing about 8,000-10,000 tonnes annually (both now owned by Orlando Wyndham), Mudgee has never enjoyed the reputation or tourist attraction of the Hunter (Beeston, 2000).

Poet's corner and Montrose dominate the Mudgee region in terms of hectares under vine, sales, employment and tourist attraction. With the exception of these two, Mudgee's wineries are classed as boutique or small. These include Huntington Estate, Steins, Craigmoor, Mirimar Wines, Pieter Van Gent, Platt's, Botobolar and Thistle Hill. Their annual crush averages between 50 and 150 tonnes. Employment averages below 5 employees per operator and a number of owners work full or part time in town for extra income. 
Surprisingly, while Mudgee wine appears to struggle for similar recognition to those of the Hunter, Margaret River and the Yarra Valley, many operators around Australia source at least a percentage of their grapes and even wine from the Mudgee region. It has a long history of producing good quality reds and now with the technical expertise of Orlando Wyndham the region's wine quality potential has been given a significant boost.

\section{Hunter Valley}

Vineyards first appeared in the Hunter Valley with the arrival of James Busby at Kirkton in the mid-1820s. George Wyndham followed soon after in 1830 and so began the development of Australia's oldest continually planted wine region (Beeston, 2000). The Hunter Valley produces 31 millon litres of wine annually, valued at approximately $\$ 230$ million (Dept. State and Regional Development, 2001).

The region is one of Australia's best known wine regions, largely because of its history and tourism (as one commentator states, its on the doorstep of a 4 million person market) and is home to a diverse collection of private and public operators. There are the long established family and public companies with capitalisation of up to $\$ 150$ million and a history of more than 100 years. But the area is also dotted with new, boutique wineries and vineyards with no history, little expertise but high hopes.

The Hunter Valley Vineyard Association, established in 1847 is commonly seen as the vehicle for bringing the interests of this diverse group into a relatively cohesive and highly marketable product. Nevertheless, as with all regions, there are different interests to be served. Because of this factor, some tensions exist between larger and smaller operators as they do between older and newer operators. 



\section{Findings}

\section{Knowledge of Industry $R \& D$}

The Australian wine industry is highly concentrated among four big operators. However, there are roughly another 1300 smaller operators throughout the country, a number which is growing rapidly. The critical question of this study is: how effectively is new knowledge penetrating these producers?

Figure 2: Perceived Current Pathways of Knowledge Diffusion

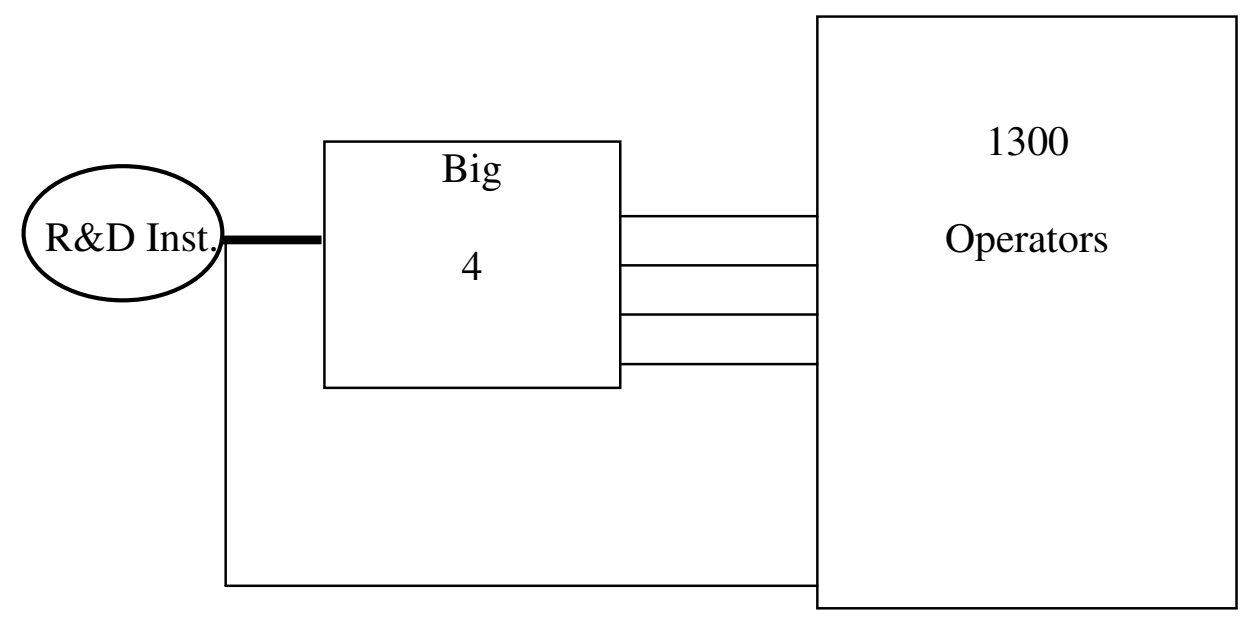

The findings from the present study confirm first impressions and concerns raised by the Committee of Inquiry into the Wine Industry (GWRDC) back in 1995, that diffusion of the substantial R\&D being carried out within the industry may be uneven and restricted. As expected, knowledge of and participation in industry R\&D activities were largely dependent upon what Turpin et al often refer to as a 'close coalition of interests' (Turpin, et al, 1995), or proximity to the R\&D 'epicentre'.

First, there was a strong concentration of awareness and knowledge within the South Australian wine regions and more particularly, Adelaide. The vast majority of industry R\&D 
is carried out by the Australian Wine Research Institute, based at the University of Adelaide. Substantial research is also carried out by the South Australian Dept. of Agriculture and the CRC for Viticulture, also based in Adelaide, although there is a node at Wagga. Little R\&D takes place outside this region and if so, it is often contracted to consultants from these bodies or the GWRDC.

Second, this concentration resides primarily with the largest wine operators. But outside these companies, those smaller operators in and around the R\&D 'epicentre' still register higher levels of awareness than their regional counterparts.

Two thirds of survey respondents (29) claimed to be aware of industry R\&D. However, at least 12 were larger operators. They were either public, large private companies or subsidiaries of public companies in regional areas, who often subsidise the research carried out and who have stronger links to the 'epicentre'. In other words, only around half of the small to medium operators claimed to be aware of industry R\&D.

Of the 12 larger operators, at least 10 had high levels of awareness concerning industry R\&D, although a number still claimed to be operating on the periphery of $R \& D$ decisions taking place in Adelaide. They claimed that although they were involved in $R \& D$ on a regular basis, and utilized industry bodies regularly, they were rarely included in the industry's R\&D decision-making processes.

The study found that there was a direct and strong association between geographic location, operator size and knowledge of industry R\&D. In other words, there was a strong and somewhat confined coalition of interests.

\section{Perceived Benefits of $R \& D$}

The survey then asked operators if they could identify benefits either directly or indirectly from industry R\&D. Less than half of the respondents claimed that they had benefited directly from industry sponsored $R \& D$, with only five small operators claiming to have done so. 
Those benefiting directly and regularly from industry R\&D were predominantly (almost exclusively) the larger operators.

What do operators expect of industry R\&D? To explore these expectations, we asked respondents how well they thought industry $R \& D$ was servicing regional operators. The majority ( 22 of the 37 who responded to this question) claimed that the service was either poor or needed improvement. All respondents with this view were small operators, who felt that industry $R \& D$ catered primarily to the large operators. It appears that while small operators have only limited knowledge of R\&D and feel they receive limited benefits from that which is carried out, they $d o$ care. They hold quite strong opinions about their need for better access to new and specialised know-how in the wine industry.

\section{Funding the Industry's Research}

In addition to government funding and other industry contributions, the Wine Industry's research and development is funded through an R\&D levy, which is paid by all operators and is levied on tonnage crushed and volume of wine.

We asked respondents to the study whether they believed the industry R\&D levy gave them value for money. Although all operators pay this levy ( $\$ 4$ per tonne) consistent with their production, it is obvious that the large operators contribute the most, in absolute terms. It could therefore be argued that they should be the major recipients of research sponsored by this levy. However, the majority of respondents argued that the wine industry was a broadbased industry and that industry R\&D should cater to this broad base by providing much needed assistance at the regional and boutique/small operator level. Almost half the respondents argued that they were not receiving value for money with the R\&D levy. The majority of these were again, small operators.

Many of the boutique/small operators had limited R\&D skills and industry training, were unaware of the opportunities for industry sponsored $R \& D$ and unfamiliar with the correct procedures for pursuing such opportunities. While they conceded that the large operators should logically receive the lion's share of $R \& D$ attention, they argued that peripheral regions 
and operators were being deprived of the opportunity to benefit from much of the new knowledge. This, they believed would undermine the current 'frontier' culture of the industry as well as future diversity.

\section{Barriers to Knowledge Diffusion}

Sentiments expressed by operators on the viability of R\&D within the industry places much of the responsibility folack of awareness, knowledge, and R\&D benefits on the GWRDC and the industry's R\&D bodies. However, this study finds that the issue is more complex. There are structural barriers, which are historically complex in nature, are common to most industry sectors and require concerted action by all stakeholders if a campaign of awareness raising is to succeed.

The interviews and surveys therefore, identified structural barriers between small operators and the 'epicentre' of research activity within the industry. These barriers included:

- lack of time;

- innovative inertia;

- absence of a research culture;

- demands of business priorities; and

- limited knowledge capacity

Time Limitations: It became evident from interviews that part of the responsibility for these breaks in knowledge flows also rest with the operators. There was evidence of what we call 'innovative inertia', particularly among the boutique and smaller operators. This type of 'innovative inertia' has been well documented in other industry sectors (Pol, 1996 \& 1999)

Research Culture: The fact that they viewed such activities as 'extra-curricula' illustrates a facet of the 'innovative inertia' which inhibits the development of a research culture. A significant number of respondents who provided negative perspectives on the above issues, admitted that they had made little or no serious attempt to raise their awareness and knowledge of industry R\&D opportunities, or procedures required for eligibility. 
Business Priorities: A number of this group also responded that they would not follow up R\&D opportunities in the future unless approached by a collaborator who was prepared to shoulder the responsibility for such collaboration. It appears that the short term viability of their business was their main priority and that $R \& D$ and its longer term implications for business activity were peripheral concerns.

Technical Expertise: Another factor influencing their attitude, was their relative inexperience and unfamiliarity with the research and education side of the industry. Some felt uncomfortable dealing in an area in which they had little expertise. It would appear that this perceived lack of technical expertise is a further inhibiting factor in generating a dynamic research culture and linkages with research agencies.

\section{Sources of Knowledge}

While the smaller operators experienced barriers to new knowledge and access to leading edge research in their field, the larger operators appeared better connected to the knowledge 'epicentre'. All large and medium sized operators, together with a small number of smaller operators claimed that industry information on R\&D outcomes was regular and up-to-date. They reported that industry journals, newsletters and special 'releases' featured the latest R\&D outcomes and technical innovations, as well as current problems being confronted by the industry. If information was unavailable from these sources, respondents claimed that the Australian Wine Research Institute had an excellent reputation for responding to operator concerns and carrying out any appropriate vine and soil tests or evaluations, for a price. These tests and evaluations were prompt and appropriate to the client's needs, although the smaller operators claimed that for them the costs were often prohibitive.

Respondents mostly echoed popular opinion that in terms of information dissemination the Australian wine industry compared favourably to such countries as France, the US and some newer world producers such as South Africa and Chile. Further, the ability to respond quickly to technical and agricultural problems had enabled the industry as a whole, to overcome many of those problems that had plagued other countries for years. 


\section{Perspectives of Small Operator Importance to Industry}

All respondents, small, medium and large were asked to comment on the importance of boutique and small operators to the future of the Australian wine industry. Boutique and small operators argued that they played an important role in the industry's development and that it is in the industry's interest to broaden and increase services to them.

A quarter of the respondents to this question said that boutique and small operators were critical to the future of the industry, while about half noted that they were important. It is not surprising that all except one who responded with critical were boutique or small operators. Only 6 respondents claimed they were either not very important or irrelevant.

The argument for their importance is based on two distinct perceptions. First, is their perceived ability to operate outside the traditional wine making parameters adopted by larger companies, with established markets and customers. Smaller operators argue that theirs is the role of breaking new ground (in terms of product), experimenting and innovating in an industry where they believe, wine making and product range is becoming increasingly standardized. Smaller operators tend to place less emphasis on market demand, have few established product lines and no quotas to meet. They therefore, have the luxury of product experimentation and variation. In short, they are the ones who take the risk. This, they argue, keeps the industry dynamic and creative.

The second perception is that a healthy wine industry requires more than a booming export market. It requires a healthy domestic base that is sufficiently broad to accommodate a variety of products, techniques, markets and future strategies. Without this broad domestic base, it is argued that the export drive will eventually falter, unable to meet growing demands for variety and complexity.

These perceptions raise an interesting paradox. On the one hand small operators see themselves at the leading edge of the industry in terms of product innovation and experimentation. Yet on the other hand, they also perceive themselves to be peripheral in 
relation to where new knowledge and training are taking place. The training aspect of this paradox is discussed in the following section.

\section{Industry Training}

Training is uniformly touted as one of the industry's most important components. Strategies for future opportunities, access and delivery are constantly on the agenda with recognition that the future of the industry is very closely tied to the future of its training capability. At least in rhetoric, results from the study support this view. For example, when asked to rank the importance of training to operators personally, respondents answered overwhelmingly that it was either critical or important. Of those who claimed it was not very important 5 of the 6 were sole operators, with no employees, no recognised training and no real ambition to expand their operations. In a recent Innovation survey, these would be described as noninnovators (ABS, 1998)

Figure 3: Importance of Industry Training to Operators

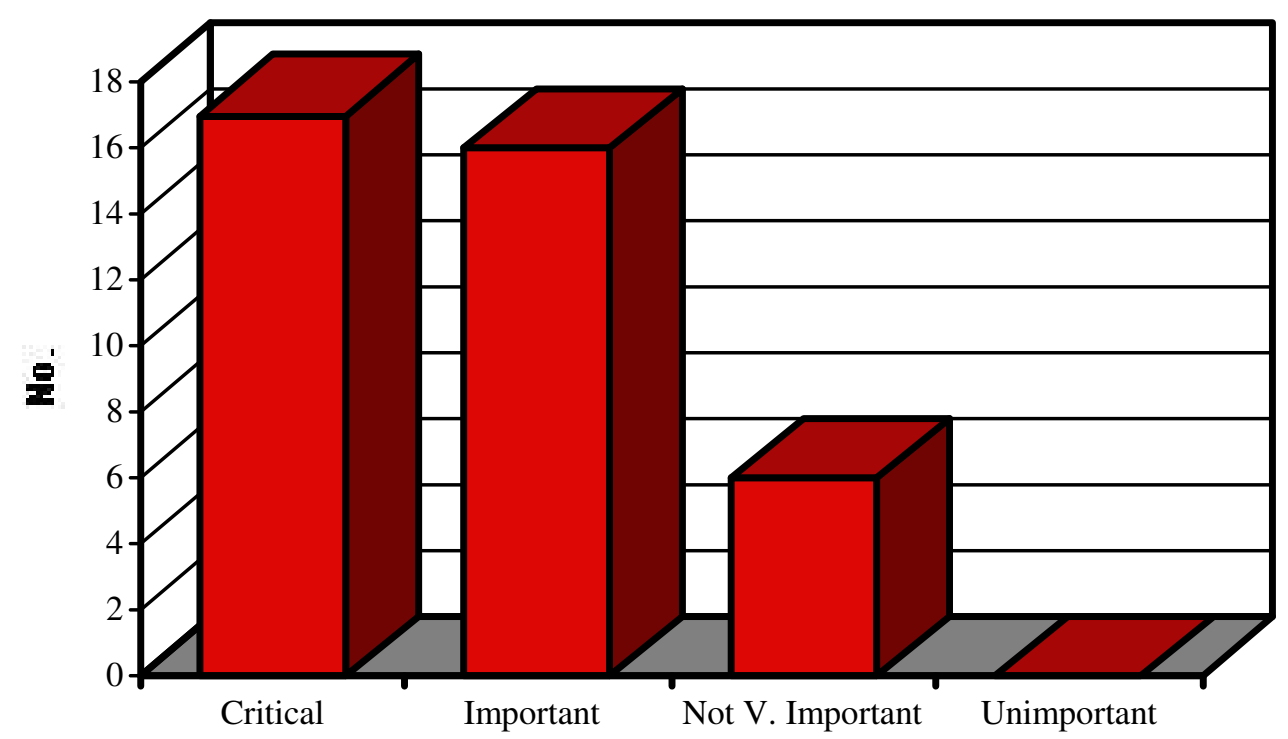

When we investigated actual training usage however, the story was somewhat different. A significant majority (24) of the 37 respondents claimed that they had not as yet made any use 
of industry training schemes. It should be noted though, that some employees were involved in training schemes at university and TAFE that were related to their employment, while not recognised as industry training schemes by the industry itself.

Reasons for non-usage of the industry training schemes:

- Awareness: A lack of awareness about what was available, although awareness was generally much higher about training opportunities than was the case with R\&D.

- Cost: Among the smaller operators, employee numbers, affordability and time away from work accounted for a large percentage of answers. Some operations simply consisted of a husband and wife team, while for others, they could not afford to sponsor employees in training and could not afford to replace them while in this training.

- Alternatives: Among the larger operators, for the few who claimed not to use training schemes, the unanimous reason was that in-house training was regarded as equivalent if not superior in standard. They argued that their training provided practical on-the-job skills suited to their particular company.

\section{Balance between Industry $R \& D$ and Training}

There was also some concern that the industry had not as yet achieved an appropriate balance between $R \& D$ and training. More than half of the respondents noted that training had to some extent been 'under-encouraged', compared with the funding avenues and opportunities being created for R\&D. Without considerably more emphasis in this area, respondents believed Australia could lose its mantle of technical expertise and innovation.

Highlighting what some claim are 'pockets' or regions where training was under-encouraged, is an example from the Hunter Valley. The Hunter is one of Australia's best known wine regions with a 160-year history and host to a number of Australia's leading wine companies. Since the closure of BHP's Newcastle steelworks, the Hunter wine industry is the area's largest employer and revenue raiser. Yet it is interesting that there is no university viticulture or wine-making curriculum within the region. Wine operators must send their employees to Maitland TAFE or utilise distance education for appropriate training. While these 
mechanisms may provide valuable learning experiences, they are structurally disconnected from those institutions with a strong research and training culture and linkages to research agencies.

The same situation has resulted in pockets of limited training opportunities in the Mudgee region as well as a number of areas in Victoria, Margaret River and Tasmania. Many employees in these regions attend TAFE rather than university courses. For example, almost half of the operators whose employees attend TAFE/university courses, claimed that the institution was not in their region. The point to be made here, is not about the quality or value of this training, but simply that it is not embedded within a research culture.

What is clear from the study's findings, is that training is an issue that requires continued and increased attention if the industry is to retain its current international image. There are areas that require immediate attention, such as course availability in regional areas and appropriate courses for all employees. An over-riding requirement however, is that industry bodies and operators work together to lift the level of awareness of training access and opportunities.

\section{Public Sector Collaboration}

The Australian wine industry, although relatively new to university collaboration, is already recognised as a world leader in establishing productive and sustainable alliances. One of the prime reasons for this success can be traced to the industry's high profile intermediary body, the GWRDC. Other factors include its historical ties with the prestigious Roseworthy College based at the University of Adelaide and the CRC for Viticulture, also based at the University of Adelaide with a node at Charles Sturt University in Wagga, NSW.

The industry's collaborative model is being increasingly sought and used by other 'New World' producers, such as California, South Africa and New Zealand (Select Committee on California Wine Production and Economy, 1994). 


\section{Collaborative Comparisons}

It should be noted, that when compared with other industry sectors we have studied, this level and breadth of industry-university collaboration, at this stage of the collaborative path, is well above average (Mohanak \& Aylward, 2001). Even those industry sectors with long and established collaborative track records have only recently broadened these partnerships to include Small to Medium Enterprises (SMEs). Historically, relationships have been confined to the largest operators with significant R\&D departments of their own. Already the wine industry is showing signs of breaking this pattern.

Figure 4: Intention of Collaborating with University partners in the futures

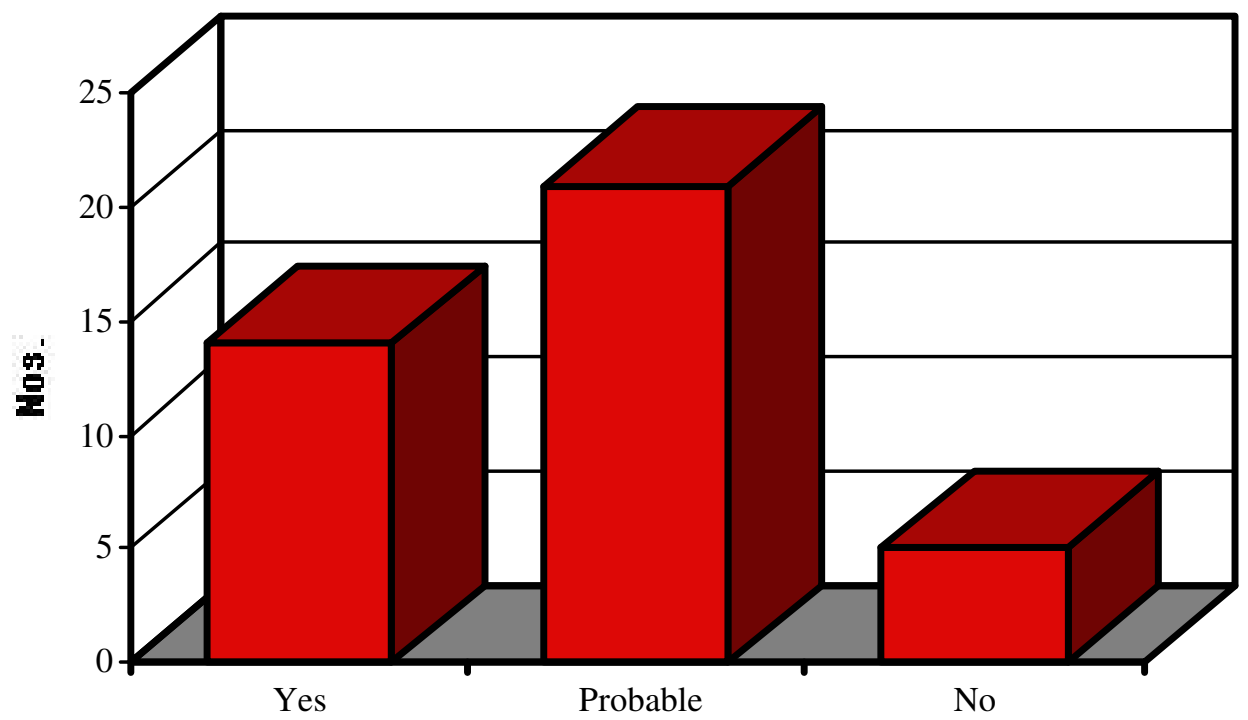

\section{Regional Collaboration}

Although almost half the respondents have, or are currently collaborating and the majority intend to collaborate in the future, most still believe that collaborative links are limited at the 
regional level. Of those who responded to this issue, two-thirds said collaborative activity within their region is low.

\section{Figure 5: Perception of Regional Collaboration}

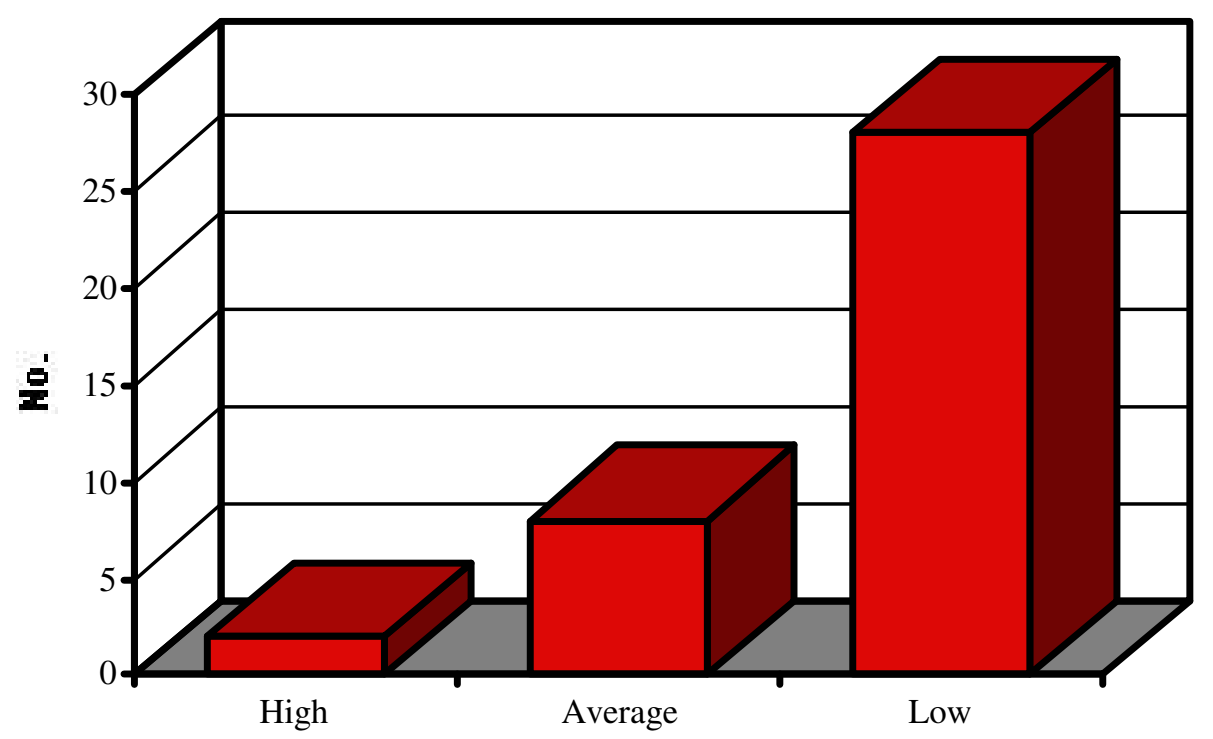

These perceptions appear to indicate that although a relatively high degree of collaboration is taking place within the industry, it is firstly, a relatively new phenomenon for the majority of operators. The collaborative culture is still someway from becoming entrenched within the industry psyche. Secondly, a number of the respondents who believed collaborative activity was low at the regional level, were those operating outside the R\&D 'epicentre', where collaboration was indeed lower.

These two points go some way to explaining the apparent discrepancy in R\&D participation and reinforce previous observations concerning knowledge diffusion. They also substantiate operator concerns over the industry's $R \& D$ concentration. $R \& D$ in the wine industry is strong but patchy. There are pockets of significant R\&D strength and concentration, but also pockets of weakness and relative neglect.

In terms of collaboration with public sector bodies, the wine industry is now at a critical stage in its evolution. Other industry sector analysis has demonstrated that awareness of opportunity is the key ingredient to developing sustainable partnerships. Our studies have also shown that as opportunity is expanded, particularly to small and medium enterprises, participation rates 
increase accordingly (Mohanak \& Aylward). There is a direct positive association between opportunity for and participation in collaboration. In a recent study of university-industry links, it was clear that a campaign of raising awareness of available collaborative schemes, together with significant increases in funding from the federal government over an eight year period, encouraged a dramatic rise (eight fold) and broadening in participation (Turpin \& Aylward,et al, 1999). This increase in participation was across all industry sectors, although in varying degrees.

\section{Option}

The wine industry has the great advantage of intermediary bodies such as the GWRDC. It must continue to use such bodies to advantage if it is to overcome the sporadic and patchy nature of $\mathrm{R} \& \mathrm{D}$ so common to institution-industry collaboration. It appears that the great challenge now for the GWRDC and the industry in general, is it to work with operators to extend and link R\&D and training opportunities systematically through sustainable mechanisms to those regions outside the 'epicentre'. One option here is to follow the example of Iceland, where there is a requirement that institute researchers (whether government or cooperative) at the centre of $R \& D$ activity, spend approximately one day per week visiting small firms to discuss relevant issues (grateful to an anonymous reviewer who drew this requirement to my attention).

The breadth, more than the depth, of the industry's R\&D culture needs to be strengthened. This will help to create greater consistency in product quality, technical innovation and adoption, as well as provide a broader platform for the industry's increasing export presence.

The need for such an initiative is certainly reinforced by the operators themselves, who overwhelmingly support the idea of greater institution-industry collaboration at the regional level. Of the 37 responses to this issue, 30 claimed that there was a real need for greater collaboration within their region. Of these 30 respondents, a significant majority stressed that these $R \& D$ initiatives should be linked to a range of training instruments by enabling regional colleges and universities to act as training nodes for the identified R\&D institutions. This 
would ensure that the latest thinking on R\&D initiatives is embraced within the curricular of these regional education bodies.

Regional TAFE colleges and industry training programs, if linked effectively, could thus act as a 'trigger point' for greater interaction between local innovators and core R\&D institutions. This absence so far, is the weak link that we have identified consistently throughout the study, but the potential of a 'training lever' is one feasible way of resolving the ' innovative inertia' problem. Linking regional training institutions into core R\&D activity could act as a catalyst, creating more seamless knowledge flows between industry bodies and regional operators and hopefully provide the technical expertise that their innovation requires. This is essential not only for the regional operators, but for the health of the industry as a whole. To succeed over the next decade, the Australian wine industry must ensure that its leading edge innovation is diffused as broadly and as uniformly as possible.

\section{Conclusion}

While the industry's R\&D and training efforts have considerably enhanced the sector's international business, and maintained the industry's image as a world leader in product, innovation and variety, there are also some inherent weaknesses in its organisational structure. These require immediate and ongoing attention in order to avoid the fragmentation and dislocation evident in many of its international competitors. It was the intention of this study to investigate some of these weaknesses and how they impact the diffusion of knowledge within the industry.

In investigating these issues, the study provides an overview of the major mechanisms by which knowledge is diffused within the industry. These mechanisms include:

- public arena knowledge;

- the industry's current training status;

- regional operations; and

- the level and 'health' of collaboration between the industry and public research bodies. 
The study identifies an interesting paradox. Many smaller operators consider themselves to be at the leading edge of product innovation and experimentation. They see themselves as 'frontier' operators, able to develop niche brands and not restricted by the standardisation and market demands of the larger operators. Yet these same operators also see themselves at the periphery of $R \& D$ activity within the industry. They are unable to develop and extend upon the linkages between research and training which the larger operators have developed so successfully.

\section{Overview of Knowledge Diffusion to Regional Operations}

Findings of the $R \& D$ overview substantiated the wine industry's popular image as a world leader. In terms of innovation, technical expertise and problem solving capability the Australian wine industry has set new international benchmarks for R\&D. It deserves its recognition for leading edge work. However, the findings also substantiated previous concerns of the Committee of Inquiry into the Wine and Winegrape Industry, that this R\&D is concentrated to a large extent in what appears to be an R\&D 'epicentre', ie among the major regions of South Australia and the industry's largest operators. Regions and operators not connected to this 'epicentre' are relatively disadvantaged.

However, it should also be noted that these smaller 'regional' operators have themselves demonstrated a degree of 'innovative inertia'. In some cases, genuine impediments such as a lack of capital, human resources and lack of awareness have prevented their involvement. The overriding issue however, appears to be a dislocation between research and training at this end of the industry.

\section{Training Status}

Training was a significant issue for the study's sample operators. The Australian wine industry enjoys a very high level of well-trained graduates in Wine Science and Viticulture. These graduates, usually from the prestigious Roseworthy and Charles Sturt campuses, are in demand both throughout Australia and increasingly overseas. 
Training was viewed by some as inadequate in regional areas and sometimes inappropriate to the needs of regional operators. Again, the more critical issue from an innovation system perspective, is the disjunction between the research and training carried out at research institutes, and the training in regional centres. Efforts to encourage linkages of such training with core R\&D centres will improve and broaden dissemination of knowledge. It should be stated that the CRC for Viticulture and the GWRDC have to date, done an excellent job of bringing together industry and academic research in a meaningful and in fact, world leading way. This is not in question. What is suggested is that this model of interaction be extended and stylised to encompass those innovators who currently reside on the periphery of knowledge diffusion.

\section{$R \& D$ Collaboration}

Where the industry appears to be showing real international leadership, is in collaboration with public sector research providers. Although a relatively newcomer to collaborative activity with the public sector, the wine industry is already setting benchmarks for other industry sectors and in particular, for its international competitors. To sustain this pattern however, considerably more focus needs to be placed on collaboration in regional areas. Without ongoing momentum generated from the industry's R\&D bodies, any move towards broader, regionalised collaborative activity is unsustainable.

Regional training and knowledge diffusion centres could offer a 'trigger' for further enriching collaboration in new and growing niche areas of wine production. This would not only enrich the knowledge flows to niche wine operators, but would also help to steer research into new and relevant areas. 


\section{Bibliography}

ABS, Innovation in Manufacturing, Australia, 1998

Anderson, K. Export-Led Growth - Lessons from Australia's Wine Industry, Rural Industries Research and Development Corporation 2000

Australian Wine Online, Web Site, http://www.winetitles.com.au/awol/ 2001

Australian Wine Research Institute, Home Page, http://www.awri.adelaide.edu.au// 2001

Beeston, J. A Concise History of Australian Wine, $3^{\text {rd }}$ edition, 2001, Allen \& Unwin, UK

Committee of Inquiry into the Winegrape and Wine Industry, Winegrape and Wine Industry in Australia, 1995, AGPS, Canberra.

Gibbons, M., Limoges, C., Nowotny, H., Schwartzman, S., Scott, P. and Trow, M. The New Production of Knowledge: The dynamics of science and research in contemporary societies, London, Sage, 1994

Grape and Wine Research and Development Corporation (GWRDC), Annual Report, 199899, 1999, Canberra

Grape and Wine Research and Development Corporation (GWRDC), Annual Operation Plan $1999 / 2000$

Gregor, S. The Lower Hunter Valley, The Australian and New Zealand Wine Industry Journal, 1996

Halliday, J. Australian and New Zealand Interactive Wine Companion, 1999, Harper Collins Publishing

Leydesdorff, I. And Etzkowitz, H. (eds), Universities in a Global Knowledge Economy: A Triple Helix of University-Industry-Government Relations, University of Amsterdam, 1996 
Mohanak, K., Aylward, D., Garrett-Jones, S., Turpin, T. Regional Innovation: Experiences of Smaller Firms in Non-Metropolitan Australia, $R \& D$ Managament Conference, Conference Proceedings, 2001, Wellington, NZ

Osmond, R. and Anderson, K.Trends and Cycles in the Australian Wine Industry, 1850 to 2000, 1998, Centre for International Economic Studies , Adelaide.

Pol, E., Crinnion, P., and Turpin, T. Innovation Barriers in Australia: What the Available Data Say and Do Not Say, IBRI Working Paper No.3, 1999

Pol, E., Garrett-Jones, S., Turpin, T., Mikus, S. Raising R\&D in Australia: Analysis of Innovation Impediments and Incentives Among IR\&D Board Client Groups, A Report to Ausindustry, 1996

Prime Minister's Science, Engineering and Innovation Council, The Australian Wine Industry - Success through Industry Leadership, Planning and Innovation, Fourth Meeting, 26 Nov. 1996, Canberra

Turpin, T., Aylward, D., Garrett-Jones, S., Johnston, R. Knowledge-Based Cooperation: University-Industry Linkages in Australia, 1996, Department of Employment, Education, Training and Youth Affairs,

Turpin, T., Aylward, D., Garrett-Jones, S., Speak, G., Grigg, L., Johnston, R. University and Industry Research Partnerships in Australia: An Evaluation of ARC/DETYA Industry-Linked Research Schemes, 1999, Canberra, AGPS

Turpin, T., Lian, Y., Tong, J. and Fang, X. Technology and Innovation Networks in the People's Republic of China, Journal of Industry Studies, Vol 2, No. 2, pp.63-74, Dec. 1995 